\title{
Caracterização do modelo de contusão medular direta quanto à dor mielopática no rato
}

\author{
Acadêmico: Fernando Onuchic \\ Orientadores: Chary Ely Martin Marquez Batista, José Pinhata Otoch, Alexandre Fogaça \\ Cristante, Guilherme Alves Lepski
}

Introdução: A lesão da medula espinal é uma afecção neurológica altamente incapacitante, que geralmente resulta em limitação importante da qualidade de vida dos pacientes. Além do déficit motor e sensitivo, a dor neuropática constitui parte central do quadro sintomatológico. Essa é causada por hiper-excitabilidade de neurônios de amplo espectro do corno posterior da medula espinal. Trata-se de condição incurável e de difícil manejo clínico. Assim sendo, o desenvolvimento de modelos experimentais em dor central mielopática é de suma importância para melhor compreensão da fisiopatologia envolvida e para elaboração de estratégias terapêuticas mais resolutivas.

Objetivos: Determinar se o modelo de contusão medular direta é adequado para o estudo de dor mielopática.

Metodologia: Ratos wistar adultos foram submetidos a lesão medular traumática, utilizando NYU Impactor. 9 animais sofreram lesão medular moderada (altura do pêndulo de $25 \mathrm{~mm}$ ), 12 sofreram lesão leve (altura de 12,5 mm), 6 foram submetidos a laminectomia sem lesão medular (sham) e 5 atuaram como controles. Em seguida, todos os animais foram avaliados através da escala motora BBB e filamentos de Von Frey durante 8 semanas. Ao fim desse período, os animais foram sacrificados através de perfusão trans-cardíaca, suas medulas espinais foram extraídas e processadas por imunohistoquímica de fluorescência.

Resultados: A avaliação da motricidade, através da escala BBB, demonstrou uma recuperação motora parcial e espontânea de ambos os grupos lesionados; contudo, o déficit motor do grupo LM foi significativamente maior que do grupo LL $(\mathrm{p}<0,01)$. Quanto à sensibilidade dolorosa, avaliada pelos filamentos de Von Frey, notou-se estabelecimento de alodinia mecânica (hiper-sensibilidade tátil) após uma semana, que perdurou pelas 8 semanas de teste ( $\mathrm{p}<0,05 \_$lesão x controles). Entre os grupos lesados, o grupo LM apresentou um quadro doloroso progressivo maior que o grupo LL ao longo das 8 semanas $(\mathrm{p}<0,05)$. Não observamos alteração significativa no teste de tail flick. Em relação à análise morfológica tecidual, a marcação tecidual por HE mostrou uma lesão mais extensa, de cerca de $0,6 \mathrm{~cm}$ no grupo LM, e $0,5 \mathrm{~cm}$ no grupo LL ( $\mathrm{p}<0,05$ ). Por fim, a quantificação de NeuN através da estereologia revelou diminuição significativa no número de neurônios na área da lesão, em comparação com grupos controle e sham; ademais, notamos menor população neuronal no grupo LM em relação ao LL $(\mathrm{p}<0,001)$. Nos níveis acima e abaixo da lesão, não foi observada diferença entre os grupos.

Discussão e conclusão: Os animais submetidos à lesão medular moderada apresentaram maior gravidade na escala motora BBB, bem como um quadro álgico mais acentuado e duradouro em relação aos animais submetidos à lesão leve. Esses resultados são explicados por maior perda neuronal no grupo com lesão moderada. Importante mencionar que não houve perda significativa de animais nos dois grupos, e o quadro álgico se manteve ao longo das 8 semanas de observação. Assim, nosso estudo sugere que a lesão medular moderada traumática direta é um bom modelo animal para estudos de dor neuropática secundária à lesão medular. Tal observação é importante para estudos subsequentes de manipulação experimental, visando um controle mais eficaz desse grave e prevalente quadro álgico. 